\title{
LA BANCA EN LA SOMBRA
}

\author{
THE SHADOW BANKING SYSTEM \\ Víctor Manuel Giudice BacA* \\ Docente Principal de la Facultad de Ciencias Económicas \\ Universidad Nacional Mayor de San Marcos-UNMSM / Lima-Perú \\ [Recepción: Abril 2016/ Conformidad: Mayo 2016]
}

\section{RESUMEN}

La Banca en la Sombra es un sector financiero emergente con grandes fondos que compiten con el Sistema Bancario, tales como AFPs, Cooperativas, Banca de Consumo, Tarjetas de Crédito de Consumo, Sociedades Agentes de Bolsa (SAB), Fondos Mutuos, Cajas Municipales de Crédito, CRACs y; en los países desarrollados, grandes consultoras devenidas en fuentes de financiamiento y emisión de valores. La Banca en la Sombra de Estados Unidos ya posee un $36 \%$ de los activos totales del Sistema Bancario y en la Eurozona un 39\%, en el Perú crece fuera de la regulación de las autoridades de supervisión. La Banca en la Sombra surgió en los países desarrollados debido a excesos de regulación del sistema bancario; tasas de interés bancarias a los depósitos que no cubren la inflación; cambio tecnológico más acelerado en la Banca en la Sombra que en el sistema bancario formal; fuerte atracción de gerentes y personal calificado del sistema bancario a la Banca en la Sombra. Se compone de instituciones que empiezan a transar operaciones entre sí: las AFPs obtienen Bonos y Valores de las SABs; las AFPs compran Pólizas de Seguros; las AFPs aumentan (apalancamiento) los Fondos Operativos del sistema bancario formal. La banca extranjera de crédito al consumo - Saga Falabella tiene ya seis millones de tarjetas de crédito en el mercado internacional. Banco Azteca y las ONG de Microcrédito se suman al sector emergente de la Banca en la Sombra.

\section{Palabras Clave:}

Shadow Banking; Banca Paralela; tamaño de la Banca en la Sombra.

\begin{abstract}
The shadow banking system is an emerging financial sector with large funds that compete with the Banking System, such as AFPs, Cooperatives, Consumer Banking, Credit Cards, Stock Brokerage Firm (SBF), Mutual Funds, Municipal Banks credit, CRAC, and in developed countries large consulting firms turned into sources of financing and securities issue. The US Shadow Banking system already owns $36 \%$ of the total assets of the Banking System, in the eurozone a 39\%, in Peru it grows out of the regulation of the supervisory authorities.

Shadow Banking System emerged in developed countries due to over-regulation of the Banking System, the lack of coverage of inflation on bank deposits interest rates, the quicker technological change than the formal Banking System; the strong attraction of managers and qualified personnel from the Banking System towards the Shadow Banking System. It is composed of institutions beginning to settle transactions among themselves: AFPs obtain bonus and securities from the SBFs; AFPs buy insurance policies; AFPs increase (leverage) the Operating Funds from the formal Banking System. Foreign banks consumer credit - Saga Falabella already has six million credit cards in the international market, Banco Azteca and Microcredit NGOs add to the emerging sector of Shadow Banking System.
\end{abstract}

\section{Keywords:}

Shadow Banking System; Parallel Banking; size of Shadow Banking System.

\footnotetext{
* Doctor en Ciencias Económicas y Políticas - Universidad de Budapest, Hungria. Economista - UNMSM . Email: vgiudiceb@unmsm.edu.pe
} 


\section{INTRODUCCIÓN}

La banca en la sombra es un nuevo fenómeno que está escapando de las autoridades de control, como la Superintendencia de Banca Seguros y AFP. y También de la Superintendencia del Mercado de Valores (SBS y SMV). La situación en el Perú es similar a la existente en Estados Unidos, Inglaterra, Holanda y la Unión Europea. El presente estudio investiga estos cuatro casos. En el se han identificado las causas del surgimiento de la banca en la sombra (banca paralela) y se han planteado algunas recomendaciones para evitar el mayor riesgo del futuro: un colapso delos fondos de pensiones que no invierten en propiedades, edificios, centros comerciales sino en papeles, bonos del gobierno, pólizas, bonos corporativos, etc.

Las recomendaciones de control se refieren a una transparencia semestral de balances auditados para las AFPs. Asímismo, quiere decir "invertir en ladrillo" (encementar) los recursos de las AFPs. También se ha encontrado que las AFP de Chile son grandes inversionistas de CENCOSUD, empresa chilena propietaria de Wong (Perú), Plaza Vea y 40 centros comerciales en América Latina. Se ha propuesto que las AFPs construyan edificios empresariales, con grandes rentas anuales. Se considera muy estratégico que las AFPs sean concesionarias de peajes y de la administración de aeropuertos. Es muy conveniente orientar a las AFPs a los negocios de bienes raíces de alto nivel: hoteles 5 estrellas, aeropuertos, edificios empresariales y propiedades de centros comerciales.

La banca en la bombra no posee acceso al fondo de seguro a los depósitos ni en el Perú, ni en los Estados Unidos ni en Europa. El riesgo es que ofrezcan altas tasas de interés superiores a la banca formal, aumentando el riesgo de crisis del sector financiero en su conjunto. En el Perú el sector bancario formal ha creado empresas que le proporcionan negocios $y$ fuente de fondos: AFP, seguros, sociedades agentes de Bolsa (SABs) y en el caso de INTERCORP se ha asociado a CENCOSUD en la propiedad de los centros comerciales Plaza Vea.

\section{SHADOW BANKING}

El sistema financiero peruano se compone de instituciones apalancadas: los depósitos y captaciones de fondos del público superan en 10 a 1 (como máximo) la relación depósitos/capital.El sistema de banca múltiple (1992) ha creado negocios bancarios que estaban "prohibidos" por casi 60 años (1932-1992). Luego de esto, los bancos incursionaron en nuevas áreas de negocios. En un solo banco se pueden realizar hoy operaciones de banca de inversión, banca del consumidor, banca comercial, banca con venta de seguros, banca inmobiliaria, y crear empresas financieras y de bolsa, así como AFPs (Administradoras de Fondos de Pensiones). El sistema bancario peruano se convirtió así en un sistema bancario "escoltado" por empresas captadoras de fondos adicionales captados en el sistema bancario. El sistema bancario "Escoltado” (shadow banking) es más poderoso y disminuyó los riesgos bancarios, los fondos de las "escoltas" están fuera del riesgo bancario, en especial, los fondos de pensiones y los fondos mutuos que fluyen al sistema bancario sin costo inmediato ( pensiones, seguros, sociedades agentes de bolsa, fondos mutuos, rentas hipotecarias, etc.). Las AFPs en conjunto han logrado apalancar al sistema bancario (aumentar el capital de trabajo). En algunos casos los depósitos de los fondos de pensiones superan ya el capital pagado de los bancosmedianos y pequeños. las "escoltas" (empresas de propiedad de los bancos) modificaron la banca tradicional. Los depósitos del público y depósitos de las empresas en el sistema bancario dejaron de ser la fuente tradicional de fondos en los últimos 13 años (1992-2015). Un estudio del FMI (FMI, 2015) ha encontrado que los fondos de las escoltas bancarias en los Estados Unidos son el 10\% de los fondos tradicionales de depósitos, mientras que en Europa la proporción de depósitos captados por las escoltas es $70 \%$ frente a los depósitos tradicionales, (FMI, 2015: 27). Un hallazgo adicional del estudio del FMI "La banca en la sombra" es que las empresas escoltas del sistema bancario han empezado a tener operaciones entre sí. Es decir, las Sociedades Agentes de Bolsa ( $\mathrm{SAB}$ ) venden acciones y bonos a las AFP y también bonos hipotecarios y pólizas de seguros (FMI, 2015: 47). 


\section{Evaluación de la Banca "Paralela" Banca en la Sombra o Banca Escoltada}

Un estudio del Banco Federal de Nueva York (NY, Fed; 2012) investigó la literatura de la "banca en la sombra" y encontró que los bancos han creado firmas a las cuales la autoridad de control (SBS) no puede regular o hay vacíos legales para exigir, por ejemplo, garantías a futuro a las AFPs. Por otro lado, encontraron que se crean "bancos para créditos al consumo" sin locales o edificios bancarios de garantía, pues no tienen qué garantizar (no captan depósitos) como el caso del Banco Falabella o el Banco Azteca en el Perú. El crédito del sistema de banca en la sombra se está expandiendo fuera del sistema bancario. El peligro es que las AFPs hagan inversiones en industrias y otras que arrojen pérdidas, y no haya, como en los bancos, depositantes que reclamen sus fondos. En las AFPs todos los resultados son a futuro. Y no hay garantías físicas para este(edificios, centros comerciales propios, urbanizaciones propias, etc.). La importante revista The Economist entrevistó al gobernador del Banco de Inglaterra en enero de 2016. (diario Gestión, Perú, 02 febrero 2016). La revista consideraba que la crisis financiera 2008 - 2016 fue creada en parte por la banca en la sombra (shadow banking). Sin embargo, bien reguladas, se podría evitar la siguiente crisis. El gobernador Mark Carney identificó a la banca paralela o "la banca de la sombra", como el mayor peligro mundial. Se refirió a la creciente expansión de la banca "paralela" en China y otros países emergentes. Por sus compras, los "shadow banks" pueden ser un peligro en las bolsas: manejan fondos muy grandes, sin garantías en "cemento". También informa Mark Carney que se presentan nuevas empresas que ofrecen fondos y administran fondos de terceros que no son bancos, ni financieras ni AFPs, sino sistemas móviles (celulares de pago), bonos ofrecidos por firmas de alta tecnología directamente al público, etc. Como por ejemplo de ello, el 28 de enero2016 la primera firma productora de marihuana en Estados Unidos lanzó a la cotización sus acciones en la Bolsa de Wall Street.

La propuesta de Mark Carney es que la regulación, control, supervisión, y aumentos de garantías, alcance al conjunto de empresas no bancarias que están incursionando en inversiones, en bolsa y crédito a los consumidores.

En contrastes la "banca - banca", es decir, la banca que no ha creado escoltas en su entorno, está sufriendo pérdidas y un mayor "acoso" de regulación, aumento de capitales y control de carteras de colocaciones muy estrictas.

\section{LA BANCA SOMBRA EN PERÚ}

La Superintendencia del Mercado de Valores (SMV) define la Banca en la Sombra como las instituciones que operan en el mercado financiero sin regulación. (SMV, 2015). La SMV considera que la "banca en la sombra" es un sistema, esto es un conglomerado de firmas. Este conglomerado, actúa como un banco y replica la "intermediación del crédito" sin protección pública. Los bancos en la sombra, con excepción de los AFPs no captan fondos de la población. Se puede argumentar que la "shadow bank" está protegida por las firmas de prestigio y solvencia que las ha creado tales como: Banco de Crédito, Intercorp, Banco Continental, etc. Esta protección es implícita, pero la ley no las obliga (enero 2016).

En el caso de Chile, los créditos "paralelos" no bancarios representan el $40 \%$ de los créditos al consumo del sistema bancario. Saga Falabella, informa Zambrano Berendson (SMV), tiene aproximadamente 6 millones de tarjetas de crédito en el mercado internacional. Un gran peligro es que las firmas de la banca paralela no aporten información a las centrales de riesgo sobre sus clientes.

Tabla No 01:

La banca en la sombra en el mundo 2012 (billones de \$USA)

\begin{tabular}{|l|c|c|}
\hline & $\begin{array}{c}\text { Activos } \\
\text { Totales }\end{array}$ & $\%$ \\
\hline 1. Bancos & 95 & 46.12 \\
\hline 2. Shadow Banks & 60 & 29.13 \\
\hline $\begin{array}{l}\text { 3. Seguros y pensiones en } \\
\text { manos privadas }\end{array}$ & 39 & 18.93 \\
\hline $\begin{array}{l}\text { 4. Instituciones públicas } \\
\text { financieras }\end{array}$ & 12 & 5.83 \\
\hline 5. Total activos & 206 & 100 \\
\hline
\end{tabular}

Fuente:The Economist.Electronic Edition. 24 enero,2016. 
Tabla No 02:

Tamaño de la banca en la sombra (\%) 2013

$($ tamaño del sistema bancario $=100)$

\begin{tabular}{|l|c|}
\hline & $\%$ \\
\hline 1.Estados Unidos & 37 \\
\hline 2. Eurozona & 33 \\
\hline 3. Reino Unido & 12 \\
\hline 4. Asia & 5 \\
\hline 5. China & 3 \\
\hline 6. Otros & 8 \\
\hline
\end{tabular}

Fuente: Banca en la sombra: prestamistas no bancarios acuden al mercado ante la brecha de créditos. www.sustainanalytics.com

También se sabe que los grandes supermercados de Chile atribuyen gran parte de sus ventas a las tarjetas de crédito de la "banca paralela".

La banca formal está contrayéndose en el mercado crediticio a causa de la crisis 2008-2013. La "banca en la sombra" regresa y crece en el mercado aumentando el riesgo sistémico. En China, la "banca en la sombra" ha crecido explosivamente. Jing Jiang expuso este peligro en la revista The Economist (10/ Mayo/2014). El título del artículo era "Shadow Banking: Batalla en la Oscuridad".

\section{CAUSAS DEL SURGIMIENTO DEL SHADOW BANKING}

Los expertos opinan que las causas pueden variar por países, pero siendo Europa y los Estados Unidos los centros de mayor desarrollo de la banca paralela, se pueden generalizar las siguientes causas:

1. Excesos de regulación a los Bancos.

2. La demanda de créditos al consumidor: son atendidas más rápidamente por los centros comerciales y sus tarjetas de crédito. Es importante recordar que el gasto de las familias está destinado en un $60 \%$ al consumo.

3. Exigencias de mayores intereses a los depósitos. Los bancos pagan menos que las instituciones de la banca paralela.

4. Traslado del personal calificado de los bancos al sector banca paralela. Esto implica un área de recursos humanos más hábil que la de la banca tradicional.
5. Los costos de los bancos con alta regulación, aumentos de capital, retención de ganancias en cuentas de provisiones para malas deudas, etc, constituyen desventajas. La alta regulación no se orienta ni impacta en costos a la banca paralela.

6. La inflación no cubre los intereses pagados a los depósitos por los bancos. La banca paralela ofrece intereses según montos de inversión por los clientes.

7. IT: las Tecnologías de la información (TI) manejada por el sector de la banca paralela es más eficiente y veloz en el procesamiento y decisión de créditos que la usada por la banca tradicional.

El informe del Banco Central de Holanda señala que el Sector de banca paralela se orienta más al crédito de consumo, pero actúa con menos fuerza en la actividad financiera: Inversiones securitización (valores), crédito a empresas, fondos mutuos, etc.

El sector de banca paralela ha escapado en otros países de la red de regulaciones, pero en Holanda sólo llega a $15 \%$ del tamaño del sector bancario. La opinión sin embargo de las autoridades es que la banca paralela crea tantos riesgos al sistema bancario como cualquier otro grupo de bancos. En Estados Unidos, al igual que en la Unión Europea, el sector de la "banca en la sombra" (paralela) no participa en los fondos de seguro a los depósitos del Banco Federal.

\section{CONCLUSIONES Y RECOMENDACIONES}

1. La banca paralela "banca en la sombra" o "Shadow banking” puede continuar creciendo mientras tengan a su lado las Administradoras de Fondos de Pensiones. Las AFPs son las instituciones del sector banca en la sombra que recibe más fondos diarios que otras empresas del sector.

2. Se requiere que el conjunto de empresas del sector sea obligado a la transparencia de sus estados financieros y memorias anuales auditadas y transparentes, ya que actualmente no están obligados e incluso las cooperativas no están obligadas a asociarse.

3. Las AFPs no están construyendo activos en "cemento" (es decir, en propiedades) como sí están obligadas las empresas de seguros. 
4. Es conveniente legislar que las AFP sean dueñas de las acciones de los centros comerciales del Perú en no menos del 30\%. Este "encementamiento financiero" asegurará las pensiones e inversiones de las AFPs por los próximos 30 años.

5. Las AFP deben ser separadas de los bancos. Los bancos sólo invierten en operaciones de corto y mediano plazo. Las AFP son entidades de jubilación, de largo plazo.

6. Las AFPs deben ser concesionadas de oficio en la administración de vías y peajes de transporte público. La misma población asegurará sus pensiones a futuro, aliviando la presión de las jubilaciones a las finanzas públicas.

7. Las concesiones y "encementamiento financiero" evitarán desde hoy (2016) que las AFPs se declaren en "quiebra" hacia el año 2030.

\section{REFERENCIAS BIBLIOGRÁFICAS}

1. BCRP(2012).Estabilidad monetaria: diseño e implementación de la política monetaria pp.1012. Disponible en: www.bcrp.gob.pe/sobreelbcrp.

2. The Economist. America.com. Banco Central de Reserva del Perú se adelanta la FED y eleva la Tasa de Interés de referencia a 3.50\%10/Nov.20

3. Gestión(02 Febrero 2016). El Atractivo de la Banca en la Sombra. (Originalmente publicado el 20 de Mayo de 2014) Gestion.pe/opinión-atractivo-banca-sombra.
4. IMF Working Papers ( 5 de 1 enero de 2015). Shedding light ofShadow Banking 43 pp. Disponible en: www.imf.org/externalPubs.2015. "Luz sobre la Banca en la Sombra" ha estimado el tamaño del Shadow Banking en 26 países.

5. JING - JIANG (2014). Shadow Banking in China Battling inthe Darkness. The Economist 10 de mayo de 2014.

6. QUISPE, Z. \& BUSTAMANTE, J.(S/F) Tasa de Interés de Política Monetaria yLos Requerimientos de Encaje Revista pp. 7-10.

7. Sistema de Reserva Federal de los Estados Unidoses.global-rates.com. El “FED” o Banco Central de Estados Unidos no es propiedaddel estado como en Perú si no propiedad de diversosGrandes Bancos. Sin embargo el Gobierno nombra a los Siete Gobernadores del FED.

8. TOBÍAS,A. y ASHCROFT, A.(2012). Shadow Banking. A Review of the literature. Federal Reserve Bank of New York 38 pp. Disponible en: ww.newyorkfed.org/report580pdf.

9. ZAMBRANO, B. (Marzo de 2015). Shadow Banking. SMV, Superintendente Adjunto de Riesgo. ppt.www.iimv.org/iimv-wp-1-0 Propone medidas para introducir la Supervisión del conjunto de Empresas que forman el sector "Banca Paralela" o Shadow Banking. 